\title{
Difference between functional residual capacity and elastic equilibrium volume in patients with chronic obstructive pulmonary disease
}

\author{
M J Morris, R G Madgwick, D J Lane
}

\begin{abstract}
Background - A study was performed to determine the elastic equilibrium volume $\left(V_{r}\right)$ of the respiratory system in patients with chronic obstructive pulmonary disease (COPD).

Methods - Voluntary relaxed expiration from total lung capacity (TLC) was studied in three groups of subjects: seven patients with severe chronic airways obstruction (COPD), 10 normal subjects, and 15 subjects with restrictive disease.

Results - In the normal subjects and the patients with restrictive disease voluntary relaxed expiration from TLC stopped close to end tidal volume (FRC) and the volume expired in this manoeuvre was less than that expired in a slow vital capacity manoeuvre (SVC). In the patients with COPD the voluntary relaxed expiration continued beyond the end tidal volume (FRC) and the volume expired was not different from the SVC. Oesophageal (pleural) pressures and surface diaphragmatic EMG recordings in the patients with COPD supported the premise that relaxation was achieved.

Conclusions - In patients with COPD, end tidal volume (FRC) is higher than the elastic equilibrium volume, $V_{r}$, of the respiratory system. This is in contrast to patients with restrictive disease and normal subjects in whom end tidal volume (FRC) is close to $V_{r}$. This study shows that, in patients with severe chronic obstructive pulmonary disease, $V_{r}$ is at least as small as residual volume (RV).

(Thorax 1996;51:415-419)
\end{abstract}

Keywords: voluntary relaxed expiration, chronic obstructive pulmonary disease, flow volume loops.

The elastic equilibrium volume $\left(\mathrm{V}_{\mathrm{r}}\right)$ is the volume at which recoil pressures of the lung and chest wall are equal and opposite. It is generally considered that this is the volume reached at the end of quiet tidal expiration. In fact it has been shown in awake upright normal subjects that the volume at the end of quiet tidal expiration decreases slightly after partial curarisation. ${ }^{1}$ This suggests that in normal subjects there is a contribution to the outward recoil of the chest wall at low lung volumes by continuous inspiratory muscle tone, certainly when measurements are made in aware subjects using noseclip and mouthpiece.
In patients with stable chronic obstructive pulmonary disease (COPD) both residual volume (RV) and end tidal volume (FRC) are increased. The increase in RV is attributed to air trapping behind closed airways. Although $\mathrm{RV}$ is classically considered a static lung volume, forced expiration may be limited by the demand for an inspiration after many seconds of expiration. The mechanism for the increase in FRC above that predicted for age, height, and sex cannot be clearly adduced from the literature.

Previous work has shown that elastic recoil of the lungs ${ }^{23}$ and of the chest wall ${ }^{4}$ is reduced in patients with long standing COPD. This reduction in recoil should lead to an increase in the elastic equilibrium volume, $V_{r}$, above that which would be predicted from the patient's age, height and sex - that is, above the predicted FRC. $V_{r}$ has not been determined in patients with stable COPD, so it is not known if such patients are breathing at this increased elastic equilibrium volume - that is, whether measured FRC is equal to the elastic equilibrium volume for a particular patient with COPD. Tidal flow versus time tracings ${ }^{25}$ suggest that this is not so, and that the mechanism for at least some of the increase in FRC is the onset of the next inspiration before the relaxed tidal expiration is complete.

The main aim of this study was to determine whether the volume at which tidal expiration ends (FRC) is the elastic equilibrium volume of the respiratory system $\left(V_{r}\right)$ in patients with severe chronic airways obstruction (COPD) as has been shown to be the case in normal subjects.

\section{Methods}

SUBJECTS

Three groups of subjects were studied after informed consent had been obtained: (1) seven patients with stable chronic COPD, mean (SD) forced expiratory volume in one second $\left(\mathrm{FEV}_{1}\right)$ $33(14) \%$ of predicted, ${ }^{6}\left(\mathrm{FEV}_{1} /\right.$ forced vital capacity (FVC)) $\times 100$ of 35 (11)\%, FRC 170 (44)\% predicted. Clinical and full lung function details of these patients have been reported previously; ${ }^{2}$ (2) 10 normal subjects with FVC $101(12) \%$ predicted, $\left(\mathrm{FEV}_{1} / \mathrm{FVC}\right) \times 100$ of 87 (4) $\%$; (3) 15 patients with restrictive disease, FVC 51 (13)\% predicted, $\left(\mathrm{FEV}_{1} / \mathrm{FVC}\right) \times 100$ of 91 (7)\%. Diagnoses included kyphoscoliosis, spinal muscular atrophy, cryptogenic fibrosing alveolitis, rheumatoid arthritis, systemic lupus erythematosis, and progressive osteitis fibrosa. 


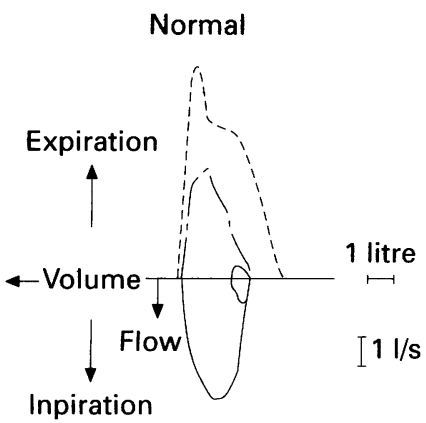

Figure 1 Representative examples of tidal (-), relaxed (-_- - - ). and forced (-- -) flow volume loops seen in normal subjects and in patients with restrictive and obstructive lung disease. In normal subjects and patients with restrictive disease the relaxed expiration from total lung capacity (TLC) ends close to end tidal volume and is roughly parallel to the forced vital capacity curve. In two typical tracings from patients with COPD relaxed expiration from TLC continues below end tidal volume to residual volume and follows a similar course to the forced vital capacity. The scale is reduced on both axes for the normal subject tracing. Slow vital capacity tracings are not shown.

EQUIPMENT

In the seven patients with COPD and two normal subjects lung volumes and airways resistance were measured in a Fenyves whole body plethysmograph and oesophageal pressures by an oesophageal balloon. In four of the seven patients with COPD and in two normal subjects EMG tracings were obtained using silver-silver chloride standard surface electrodes in the seventh right intercostal space, Electromed 4880 isolated EMG pre-amplifier, and Gould recorder (Brush 260) which had a frequency response flat up to $60 \mathrm{~Hz}$. EMG recordings were unsatisfactory in one patient and repeat studies were not possible in two patients.

Flow volume loops were recorded using flow measured by a Fleisch pneumotachograph and volume obtained by integration of the flow signal, tracings being recorded on a Bryan's $\mathrm{X}-\mathrm{Y} 50000$ (fast mode).

An oesophageal balloon was positioned in the lower oesophagus with no evidence of positive pressure on tracheal compression or abdominal contraction and with minimum cardiac artefact. The gas volume in the balloon was $0.5 \mathrm{ml}$ for the relaxed manoeuvres and $1.5 \mathrm{ml}$ for the forced manoeuvres. Oesophageal pressure was measured with the mouth/oesophagus body plethysmograph transducer relative to atmospheric pressure.

Synchronous tracings of volume, flow, and oesophageal pressure were displayed on a Gould 5 channel recorder (Brush 260). Pressure and flow tracings were in phase with the apparatus and the pens were accurately lined up on the recording paper. The frequency response of oesophageal balloon, tubing, transducer and recorder system was flat up to $5 \mathrm{~Hz}$. The pressure transducer was calibrated before each study with a water manometer and

Table 1 Mean (SD) expiratory volumes (itres)

\begin{tabular}{|c|c|c|c|c|}
\hline & \multicolumn{2}{|c|}{ Full expiration } & \multicolumn{2}{|c|}{ Expiratory reserve volume } \\
\hline & $S V C$ & Sigh & $S V C$ & Sigh \\
\hline $\begin{array}{l}\text { Normal } \\
\text { Restrictive } \\
\text { Obstructive }\end{array}$ & $\begin{array}{l}4 \cdot 6(1 \cdot 1) \\
1 \cdot 76(0 \cdot 66) \\
2 \cdot 81(1 \cdot 27)\end{array}$ & $\begin{array}{l}3.13(0.67)^{*} \\
1.19(0.49)^{*} \\
2.80(1.73)\end{array}$ & $\begin{array}{l}1.67(0.66) \\
0.6(0.23) \\
0.76(0.43)\end{array}$ & $\begin{array}{l}0.17(0.33)^{*} \\
0.1(0.09)^{*} \\
0.71(0.33)\end{array}$ \\
\hline
\end{tabular}

$* \mathrm{p}<0.001$. checked at the end and found in each case to be unchanged. Zero pressure was checked frequently during each study. Flow was measured through a Fleisch No. 3 pneumotachograph which gave a linear response up to $21 / \mathrm{s}$. The flow signal was integrated to give volume. There was no significant drift of the volume tracing against time. Flow and volume were calibrated using a one litre syringe according to manufacturer's instructions (water displacement volume of the calibrating syringe $1.031)$. In all subjects spirometric measurements were performed using the same Vitalograph spirometer and pneumotachometer.

\section{PROTOCOL}

A slow vital capacity (SVC) manoeuvre was first undertaken as a slow expiration from TLC with push at the end to achieve the maximum expired volume possible. After a period of quiet breathing the subject was then asked to breathe in to TLC and then to relax his respiratory muscles for as long as possible without holding back the expiration or pushing it (fig 1). Useful instructions were "give a sigh", "let your shoulders relax", and "relax as long as you can". The volume expired in this relaxed expiration has been called the "sigh" volume in this paper and, whilst some ${ }^{7}$ refer to the SVC as a relaxed vital capacity, we prefer to use SVC to avoid confusion between this and the sigh volume. Flow volume curves were recorded during tidal breathing, during maximal FVC expiration, and during a relaxed expiration from TLC (sigh), it being assumed that the same TLC was reached before both full expirations (fig 1). These manoeuvres were repeated at least twice.

\section{Results}

The volumes expired and the oesophageal (pleural) pressures during expiration are shown in tables 1 and 2 . In the normal subjects and the patients with restrictive disease SVC was bigger than the sigh volume. This was in contrast to the patients with COPD in whom there was no difference between SVC and the sigh volume (fig 1 ). This pattern was shown again 
Table 2 Expired volumes and pleural pressures in seven patients with COPD during FVC and SVC manoeuvres and relaxed expirations from TLC (sigh)

\begin{tabular}{|c|c|c|c|c|c|c|c|c|c|c|c|c|}
\hline \multirow{2}{*}{$\begin{array}{l}\text { Patient } \\
\text { no. }\end{array}$} & \multicolumn{3}{|c|}{ Expired volume from $T L C$ (l) } & \multicolumn{3}{|c|}{ Pleural pressure at $T L C\left(\mathrm{~cm} \mathrm{H}_{2} \mathrm{O}\right)$} & \multicolumn{3}{|c|}{ Pleural pressure at end expiration } & \multicolumn{3}{|c|}{ Most positive pleural pressure } \\
\hline & FVC & $S V C$ & Sigh & $F V C$ & $S V C$ & Sigh & FVC & $S V C$ & Sigh & FVC & $S V C$ & Sigh \\
\hline $\begin{array}{l}1 \\
2 \\
3 \\
4 \\
5 \\
6 \\
7 \\
\text { Mean } \\
\text { SD }\end{array}$ & $\begin{array}{l}4 \cdot 64 \\
1 \cdot 44 \\
1 \cdot 44 \\
2 \cdot 16 \\
3 \cdot 51 \\
2 \cdot 11 \\
2 \cdot 43\end{array}$ & $\begin{array}{l}4 \cdot 69 \\
1.55 \\
1.59 \\
2 \cdot 21 \\
4 \cdot 39 \\
2 \cdot 42 \\
2 \cdot 86 \\
2 \cdot 82 \\
1.27 \\
\text { NS }\end{array}$ & $\begin{array}{l}4.67 \\
1.61 \\
1.54 \\
3.30 \\
3.52 \\
2.15 \\
2.84 \\
2.80 \\
1.13\end{array}$ & $\begin{array}{r}-18.0 \\
-8.0 \\
-6.7 \\
-16.0 \\
-15.4 \\
-15.0\end{array}$ & $\begin{array}{r}-18 \cdot 4 \\
-22 \cdot 0 \\
-9 \cdot 0 \\
-4 \cdot 4 \\
-14 \cdot 0 \\
-21 \cdot 1 \\
-15 \cdot 0 \\
-14 \cdot 8 \\
6 \cdot 4 \\
\mathrm{NS}\end{array}$ & $\begin{array}{r}-18.7 \\
-23.3 \\
-8.0 \\
-8.8 \\
-20.0 \\
-18.0 \\
-15.0 \\
-16.0 \\
5.7\end{array}$ & $\begin{array}{r}>25 \\
6 \cdot 0 \\
20 \cdot 0 \\
8.9 \\
18 \cdot 0 \\
5.8 \\
>25\end{array}$ & \begin{tabular}{l}
$7 \cdot 6$ \\
$21 \cdot 0$ \\
$7 \cdot 0$ \\
$7 \cdot 7$ \\
$12 \cdot 0$ \\
$4 \cdot 8$ \\
$6 \cdot 0$ \\
$9 \cdot 4$ \\
$5 \cdot 6$ \\
\multicolumn{1}{c}{$p$}
\end{tabular} & $\begin{array}{r}0.4 \\
-0.6 \\
1.3 \\
1.1 \\
-2 \cdot 3 \\
-2 \cdot 4 \\
-0.5 \\
-0.5 \\
1.5 \\
005\end{array}$ & $\begin{array}{l}>25 \\
>25 \\
>25 \\
>25 \\
>25 \\
29 \cdot 0 \\
>25 \\
>25\end{array}$ & $\begin{array}{r}18 \cdot 4 \\
27 \cdot 0 \\
19 \cdot 0 \\
13 \cdot 2 \\
12 \cdot 0 \\
15 \cdot 4 \\
9 \cdot 5 \\
16 \cdot 4 \\
5 \cdot 8 \\
\text { p }\end{array}$ & $\begin{array}{l}5.0 \\
8.5 \\
7.0 \\
3.9 \\
1.5 \\
3.6 \\
2.0 \\
4.5 \\
2.6 \\
05\end{array}$ \\
\hline
\end{tabular}

FVC = forced vital capacity; SVC = slow vital capacity; TLC $=$ total lung capacity.

with the expiratory reserve volume (ERV) which was defined as the difference between end tidal volume and the volume at the end of expiration, either by the SVC manoeuvre or the sigh manoeuvre. In the normal subjects and patients with restrictive disease ERV was bigger in the SVC manoeuvre than in the sigh manoeuvre, whereas in the patients with COPD there was no difference in this volume between the two manoeuvres. In both normal and re-
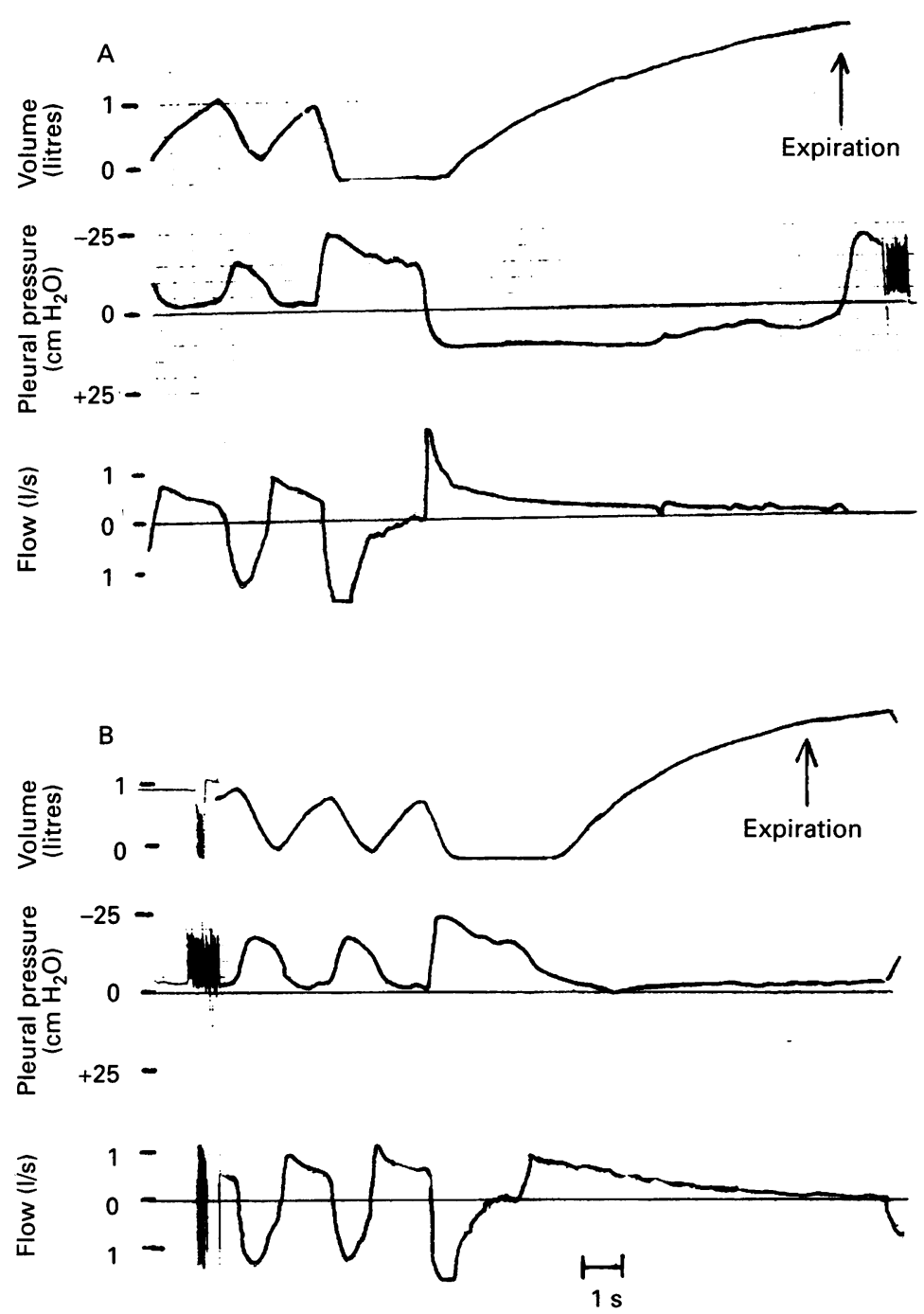

Figure 2 Representative example in subject with COPD of volume and pleural pressure tracing obtained during (A) slow vital capacity (SVC) and (B) relaxed expiration from total lung capacity (TLC). During the SVC expiration pleural pressure is positive throughout. During this attempt at a relaxed expiration pleural pressure increases only to zero and becomes more negative with decreasing lung volume. Maximum inspiratory flow amd volume reach a ceiling on this tracing because of the scaling of the $y$ axes. strictive subjects (table 1) there was a small volume difference between end tidal and end sigh volumes, confirming the previous findings in normal subjects ${ }^{1}$ that FRC is slightly larger than $V_{r}$.

In the patients with COPD and in the two normal subjects studied, pleural (oesophageal) pressures during the sigh expiration were more negative than those during the SVC expiration (table 2, fig 2). This showed that expiratory muscles were less active during the sigh expirations than during SVC expirations. Pleural pressure at end expiration SVC was quite positive and at end sigh expiration was negative (table 2). The most positive pressure during the SVC was much more positive than that measured during the sigh expiration. There was no difference between the pleural pressures at TLC before these expirations began. Typical patterns of pleural pressure during the SVC and sigh manouevres from one patient with COPD are shown in fig 2 .

EMG tracings showed that muscle activity detected by surface electrodes was clearly less during voluntarily relaxed expiration (sigh) than during SVC manoeuvres. Figure 3 shows an example of this qualitative result in one patient with COPD.

\section{Discussion}

We have shown that in patients with COPD the end tidal volume (FRC) is higher than the elastic equilibrium volume of the respiratory systems, $V_{r}$, which is in contrast to that seen in normal subjects and patients with restrictive disease where FRC is close to $V_{r}$. The validity of this result is dependent on the assurance that our subjects undertook a truly relaxed sigh expiration, and it is well known that voluntary relaxation is a difficult technique. We believe that all our subjects with COPD achieved satisfactory relaxation for three reasons. Firstly, during the relaxed expirations (sigh) of the normal subjects and the patients with restrictive disease the expected volumes were expired that is, close to FRC - suggesting that these subjects achieved relaxation (fig 1). There was no reason to suspect that the subjects with COPD understood the instructions less well or were less cooperative. Secondly, the pleural pressure measurements (fig 2, table 2) suggest that relaxation was achieved, not instantly, but within 1.5 seconds of onset of expiration in the seven patients with COPD. The pleural 

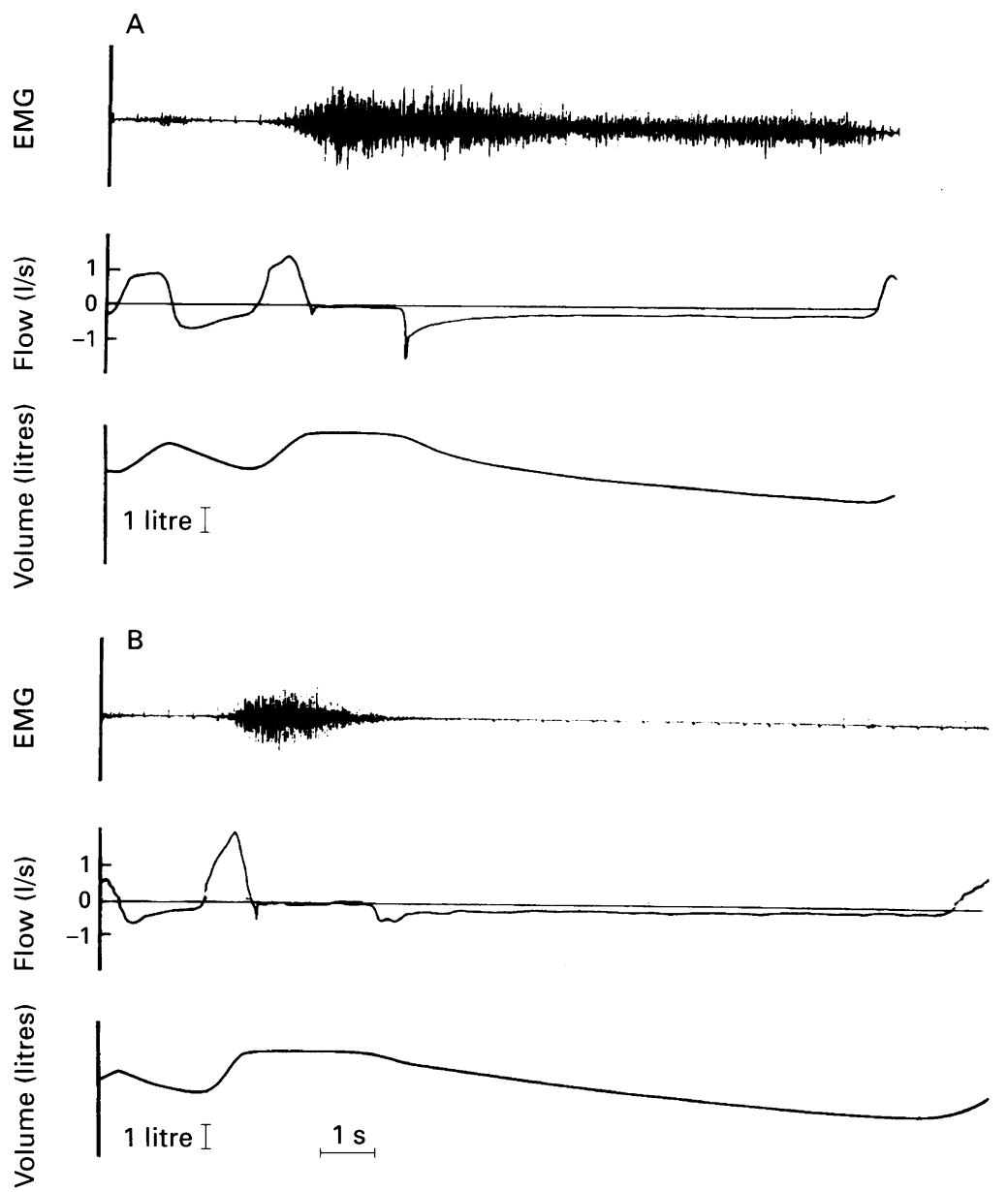

Figure 3 EMG tracing with synchronous flow and volume recording in a subject with $C O P D$ during $(A)$ slow vital capacity $(S V C)$ and $(B)$ relaxed expiration from total lung capacity (TLC). Surface electrodes show a lot of EMG activity during SVC expiration (the instruction being to push out the breath for as long as possible) and no activity during the relaxed expiration (the instruction being to relax for as long as possible). Low flows of similar magnitude were achieved during both expirations.

pressures measured during the relaxed phase of expiration showed loss of chest wall recoil relative to volume but normal chest wall compliance of $0.213(0 \cdot 125) \mathrm{l} / \mathrm{cm} \mathrm{H}_{2} \mathrm{O}$ as has been found previously in patients with COPD who were paralysed. ${ }^{4}$ In our subjects expiration continued below FRC when the pleural pressure was becoming increasingly negative. Finally, the EMG tracings clearly showed a lack of expiratory muscle activity during sigh compared with SVC expiration in both the two normal subjects studied and the patients with COPD (fig 3).

To record the EMG we used surface electrodes mainly because they are less invasive than needle electrodes. However, their lack of specificity and relative insensitivity may be an advantage in that they detect significant muscle activity in any sizeable muscle mass in their vicinity and so may give an overall view of respiratory muscle activity. For instance, electrodes placed in the seventh right intercostal space, typically thought of as surface electrodes for diaphragm activity, detected both phasic inspiratory and voluntary expiratory muscle activity. In the small number of patients we have studied these electrodes did not detect the invariable phasic expiratory activity of transversus abdominis during resting tidal breathing seen during expiration of 17 of 28 similar subjects studied by Ninane et al. ${ }^{8}$ The main problem we have had with surface electrodes is the noise to signal ratio which may be unacceptably high, making it difficult to be sure of electrical silence. This difficulty is random and we have not been able to refine the technique sufficiently to be sure of always getting records such as that shown in fig 3. However, in four patients with COPD in group 1 and six other similar patients with COPD, tracings were obtained which clearly showed muscle activity during the sigh to be much less than during SVC expiration, and apparently absent during some sighs whose expiratory volumes were equal to SVC volumes.

There is evidence in the literature relating to breathing muscle activity during tidal breathing in patients with COPD. Tidal flow/time and oesophageal/time tracings ${ }^{25}$ suggest that expiration is interrupted before it is complete by the onset of the next inspiration. Citterio et al ${ }^{9}$ have shown more rapid decay of inspiratory muscle activity in patients with COPD than in normal subjects. This work supports the idea that tidal expiration is relaxed in patients with COPD. However, there is other conflicting evidence in the literature relating to breathing muscle activity during tidal expiration in patients with COPD. Muller ${ }^{10}$ and Martin ${ }^{11}$ have suggested that there is tonic inspiratory muscle activity throughout expiration in asthma. This would suggest that FRC is greater than $V_{r}$ as a result of continuous inspiratory work being done during expiration. Recent work ${ }^{8}$ has suggested that there is contraction of the expiratory muscle transversus abdominis towards the end of tidal expiration in patients with COPD. These authors suggest that intrinsic positive end expiratory pressure $\left(\mathrm{PEEP}_{\mathrm{i}}\right)$ is due to this muscle action and is overcome by relaxation of this expiratory muscle rather than by contraction of inspiratory muscles as postulated by Dal Vecchio et $a l^{5}$ and by Morris et $a l^{2}$ Expiratory muscle action during tidal expiration would be expected to reduce FRC below $V_{r}$ unless flow limitation is present. If, as we have shown, the same expiratory flows are achieved during a relaxed expiration as during a forced expiration, expiratory muscle activity would be wasteful of effort. O'Donnell et $a l^{12}$ have suggested that both inspiratory and expiratory muscles are active during tidal expiration in patients with COPD, modulating expiratory flow so that dynamic compression, which is uncomfortable, does not occur. We have suggested ${ }^{2}$ that the intrinsic narrowing and increased compliance of the airways are enough to decrease pressure wave speed sufficiently to limit gas flow. Additional narrowing due to dynamic compression of airways is not necessary for flow limitation to occur in patients with severe COPD.

Tuxen et al $^{1314}$ have shown that if the ventilator is turned off at the end of inspiration for as long as 40-60 seconds in paralysed ventilated patients with asthma, deflation continues below FRC in the same way as occurred in this study with voluntarily relaxing COPD patients. Their study was not exactly comparable to ours as 
their patients had very severe asthma. In addition, before this manoeuvre was undertaken the FRC may have been forced up by the ventilator settings which determine expiratory time.

One conclusion from our study is that the elastic equilibrium volume of the respiratory system in patients with COPD is at least as low as RV. The relaxed expiration may stop at $\mathrm{RV}$ in patients with COPD because, at that lung volume, all airways are closed even in the absence of positive pleural pressure and true $\mathrm{V}_{\mathrm{r}}$ may be even smaller than RV. Our previous work ${ }^{2}$ and that of others ${ }^{58}$ has shown a small positive alveolar pressure just before the end of expiration in stable COPD patients (in these seven patients $\left.2 \cdot 1(0 \cdot 6) \mathrm{cm} \mathrm{H}_{2} \mathrm{O}\right){ }^{2}$ We believe that this pressure (intrinsic PEEP) has to be overcome by the action of the inspiratory muscles before the next inspiration can begin and flow reversal occur. The small intrinsic PEEP found in these patients with COPD and the findings of this study are consistent with expiration being relaxed during tidal breathing in patients with COPD and FRC being a larger volume than $V_{r}$ because the relaxed expiration is interrupted by the onset of the next inspiration. This is not incompatible with $\mathrm{V}_{\mathrm{r}}$ being itself increased due to loss of lung and chest wall recoil in patients with long standing disease. The authors thank Allen \& Hanburys Ltd for their support of
the Osler Chest Clinic Lung Function Laboratory. Richard Madgwick is Allen \& Hanburys respiratory function technician.
1 De Troyer A, Bastenier J, Delhez L. Function of respiratory muscles during partial curarisation in humans. f $A p p$ Physiol: Respir Environ Exerc Physiol 1980;19:1049-56.

2 Morris MJ, Madgwick RG, Frew AJ, Lane DJ. Breathing muscle activity during expiration in patients with chronic muscle activity during expiration in patients with

3 Finucane KE, Colebatch JH. Elastic behaviour of the lung in patients with airway obstruction. $\mathcal{F}$ Appl Physiol 1969; 26:330-8.

4 Sharp JT, Van Lith P, Nuchprayoon CV, Briney R, Johnson FN. The thorax in chronic obstructive lung disease. $A m$ f Med 1968;44:30-46.

5 Dal Vecchio L, Polese G, Poggi R, Rossi A. "Intrinsic" positive end-expiratory pressure in stable patients with chronic obstructive pulmonary disease. Eur Respir f 1990; 3:74-80.

6 Cotes JE. Lung function throughout life: determinants and reference values. In: Lung function assessment and application in medicine. Oxford: Blackwell Scientific Pubplication in medicine. O
lications, 1979:329-87.

7 Guidelines for the measurement of respiratory function. Recommendations of the BTS and ARTP. Respir Med 1994;88:165-94

8 Ninane V, Rypens F, Yernault JC, de Troyer A. Abdominal muscle use during breathing in patients with chronic airflow obstruction. Am Rev Respir Dis 1992:146:16-21.

9 Citterio G, Agostoni E, Del Santo A, Marazzini L. Decay of inspiratory muscle activity in chronic airway obstruction. $\mathcal{f}$ Appl Physiol: Respir Environ Exerc Physiol 1981;51:138897.

10 Muller N, Bryan AC, Zamel N. Tonic inspiratory muscle activity as a cause of hyperinflation in asthma. $\mathcal{f} A p p l$ Physiol: Respir Environ Exerc Physiol 1981;50:279-82.

11 Martin JG, Shore SA, Engel LA. Mechanical load and inspiratory muscle action during induced asthma. Am Rev Respir Dis 1983;128:455-60.

12 O'Donnell DE, Sanii R, Anthonisen NR, Younes M. Expiratory resistive loading in patients with severe chronic air-flow limitation - an evaluation of ventilatory mechanics and compensatory responses. Am Rev Respir Dis 1987; 136:102-7.

13 Tuxen DV, Lane S. The effects of ventilatory pattern on hyperinflation, airway pressures, and circulation in mechanical ventilation of patients with severe air-flow obstruction. Am Rev Respir Dis 1987;136:872-9.

14 Tuxen DV, Williams TJ, Scheinkstel CD, Czarny D, Bowes $G$. Use of a measurement of pulmonary hyperinflation to control the level of mechanical ventilation in patients with acute severe asthma. Am Rev Respir Dis 1992;146: with acute 